\title{
Desain Ipal Pengolahan Grey Water Dengan Teknologi Subsurface Flow Constructd Wetland Di Rusunawa Grudo Surabaya
}

\author{
Ahmad Safrodin dan Sarwoko Mangkoedihardjo \\ Jurusan Teknik Lingkungan, Fakultas Teknik Sipil dan Perencanaan, Institut Teknologi Sepuluh \\ Nopember (ITS) \\ Jl. Arief Rahman Hakim, Surabaya 60111 Indonesia \\ e-mail:Sarwoko@enviro.its.ac.id
}

\begin{abstract}
Abstrak - Pencemaran Lingkungan di Kota Surabaya akan terus meningkat seiring dengan perkembangan penduduk dan keterbatasan sarana sanitasi yang kurang baik. Pencemaran lingkungan ini didominasi limbah domestik sehingga perlu sistem pengolahan yang efektif dan efisien dalam mendegradasi senyawa polutan. Teknologi Constructed wetland merupakan sistem pengolahan terencana atau terkontrol yang telah didesain dan dibangun menggunakan proses alami yang melibatkan vegetasi, media, dan mikroorganisme untuk mengolah air limbah domestik. Teknologi ini dapat diterapkan untuk skala perumahan baik individu atau secara komunal. Rusunawa Grudo Surabaya merupakan rusun yang belum memiliki IPAL untuk mengolah greywater, sehingga sistem Contructed wetland ini dapat diterapkan untuk meningkatkan kualitas sanitasi lingkungan. Perencanaan sistem Constructed wetland di Rusunawa Grudo Surabaya mempertimbangkan aspek kuantitas dan kualitas air limbah. Kualitas air limbah domestik menunjukkan nilai COD $329.81 \mathrm{mg} / \mathrm{L}$; BOD 182.02 $\mathrm{mg} / \mathrm{L}$; dan TSS 103.33 mg/L, sedangkan kuantitas air limbah $33.6 \mathrm{~m}^{3} /$ hari. Sistem ini terdiri dari unit ekualisasi, Subsurface Flow Constructed Wetland dengan tanaman Cyperus alternifolius, dan kolam penampung. Hasil perencanaan menunjukkan efisiensi pengolahan seluruh sistem untuk COD, BOD, dan TSS masing-masing sebesar $86 \%, 85 \%$, dan $88 \%$. Desain sistem IPAL menghasilkan luas permukaan $480 \mathrm{~m}^{2}$, kedalaman bed $0,5 \mathrm{~m}$, beban pada bed (OLR) $12.75 \mathrm{gr}$ BOD $/ \mathrm{m}^{2}$.hari, beban hidrolik (HLR) $0,07 \mathrm{~m}^{3} / \mathrm{m}^{2}$.hari dengan waktu tinggal 3 hari. Kualitas efluen yang didapatkan menunjukkan nilai BOD $25 \mathrm{mg} / \mathrm{L}$, COD $48.35 \mathrm{mg} / \mathrm{L}$ dan TSS $11.72 \mathrm{mg} / \mathrm{L}$. Dihasilkan standar operasional dan perawatan IPAL dan Biaya investasi seluruh sistem constructed wetland diperkirakan sebesar Rp.412.059.022.
\end{abstract}

Kata Kunci : Constructed wetland, Cyperus alternifolius, Grey water, Limbah domestik, Pencemaran

\section{PENDAHULUAN}

$P$ encemaran Lingkungan di Kota Surabaya akan terus meningkat seiring dengan perkembangan penduduk dan keterbatasan sarana sanitasi yang kurang baik. Penurunan Kualitas air yang disebabkan oleh limbah domestik memberikan kontribusi pencemaran sebesar $60 \%$ dan limbah industri sebesar $40 \%$ [1]. Pencemaran ini terjadi karena tidak adanya sistem pengolahan, tetapi limbah yang langsung di alirkan ke badan air. Berdasarkan data status kualitas air sungai kota Surabaya, pada tahun 2013 Kali Mas Kota Surabaya status mutu kualitas air yaitu BOD (4.06 mg/l) melebihi baku mutu air kelas II yaitu $3 \mathrm{mg} / \mathrm{l}$, TSS (401 mg/l) melebihi baku mutu air kelas II $50 \mathrm{mg} / \mathrm{l}$ dan DO (2.395 $\mathrm{mg} / \mathrm{l})$ kurang dari baku mutu air kelas III yaitu > $3 \mathrm{mg} / \mathrm{l}$ [2].
Rusunawa Grudo merupakan rusunawa milik Pemerintah Kota Surabaya yang menghasilkan limbah domestik berupa limbah black water dan grey water dengan sistem saluran terpisah. Pada saat ini, limbah black water telah terdapat sistem pengolahan, sedangkan limbah grey water belum memiliki sistem pengolahan dan dialirkan secara langsung ke saluran drainase yang nantinya akan bermuara ke sungai Kali Mas Kota Surabaya. Hal ini nantinya akan berdampak pada peningkatan pencemaran kualitas air Kali Mas Kota Surabaya. Grey water adalah air limbah yang berasal dari kegiatan mandi dan cuci [3]. Karakteristik Grey water adalah memiliki zat organik yang cukup tinggi dan grey water dari dapur memiliki kandungan organik yang lebih tinggi dibandingkan grey water dari kamar mandi [8]. Menurut peraturan yang ada, setiap kegiatan usaha wajib mengolah limbah dan menjaga ekosistem lingkungan [9].

Teknologi constructed wetland dapat diterapkan sebagai teknologi pengolahan limbah greywater di perumah atau domestik [14]. Constructed wetland merupakan wetland buatan yang dikelola dan dikontrol oleh manusia untuk keperluan filtrasi air buangan dengan penggunaan tanaman, aktifitas mikroba dan proses alami lainnya [4]. Prinsip pengolahan air limbah dengan constructed wetland dengan mengalirkan air limbah di bawah media sehingga limbah akan di serap melalui akar tanaman. Instalasi pengolahan ini mampu mengolah limbah domestik dan industri dengan baik ditunjukkan dengan efisiensi pengolahan limbah yang tinggi yaitu lebih dari $80 \%$ [11]. Penggunaan constructed wetland dengan tanaman Cyperus alternifolius dapat menjadi alternatif pengolahan air limbah grey water skala rusunawa. Keuntungan yang diperoleh dari sistem ini adalah memperoleh nilai efisiensi yang tinggi dan memperoleh desain IPAL yang memiliki nilai estetika.

\section{LOKASI STUDI}

Rumah Susun Grudo Surabaya merupakan rusun milik Pemerintah Kota Surabaya yang terletak ditengah kota Surabaya, tepatnya masuk wilayah Kec. Tegal Sari Kelurahan Dr Sutomo Surabaya Pusat yang beralamat di J1. Grudo gg.V No. 2 , Surabaya. Sebelumnya lahan rusun ini merupakan lahan Dinas PU Bina Marga Kota Surabaya dan Dinas Kebersihan dan Pertanaman Kota Surabaya. Rusun Grudo ini memiliki nilai yang strategis mengingat tempatnya ditengah kota sehingga melalui paguyuban yang telah 
dibentuk memiliki pandangan bahwa rusun harus bersih dan nyaman.

Rusunawa Grudo dibangun dengan design struktur 5 lantai. Didalam rusun ini terdapat 96 unit kamar dan tiap kamar maksimal 4 penghuni dengan luas kamar $24 \mathrm{~m}^{2}$ (panjang $6 \mathrm{~m}$, lebar $4 \mathrm{~m}$ dan tinggi $3 \mathrm{~m}$ ) serta dilengkapi adanya fasilitas penunjang. Sistem buangan limbah domestik rusun ini telah terpisah antara grey water dan black water. Saluran limbah grey water dialirkan secara langsung ke drainase dan black water secara komunal menuju ke IPAL.

IPAL dengan teknologi constructed wetland akan didesain di lahan kosong dengan luas lahan tersedia $669 \mathrm{~m}^{2}$.

\section{METODOLOGI PENELITIAN}

\section{A. Pengumpulan data}

Pengumpulan data dalam perencanaan adalah data primer dan data sekunder. Data Primer dapat berupa karakteristik limbah meliputi BOD, COD, TSS, dan $\mathrm{pH}$. Pengambilan karakteristik limbah ini sebanyak 3 kali dengan 6 titik pengambilan secara composit sampling pada pagi hari. Dilakukan pengukuran luas lahan area IPAL dan mencari data debit air limbah rencana. Untuk data sekunder yang dibutuhkan adalah denah area rusunawa Grudo Surabaya, baku mutu air limbah berdasarkan Pergub Jatim No. 72 tahun 2013, jumlah penghuni rusun dan literatur sebagai dasar perencanaan.

\section{B. Perhitungan Unit IPAL}

Sistem unit IPAL yang direncanakan dilihat pada gambar 1

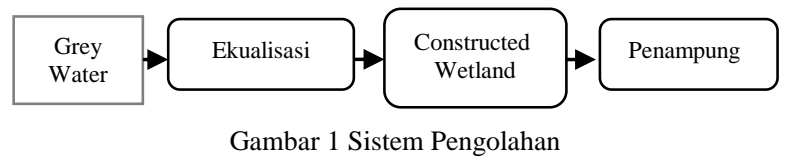

Unit IPAL yang direncakan berupa kolam ekualisasi, unit Constructed wetland, dan kolam penampungan. Kolam ekualisasi pada pengolahan berfungsi untuk menghomogenkan air limbah dan menjaga air limbah tidak berfluktuasi. Perhitungan desain kolam ekualisasi sebagai berikut:

$$
\mathrm{V}=(\mathrm{HRT} / 24) \times \mathrm{Q}
$$

$$
\begin{aligned}
\text { Dimana, } \mathrm{V} & =\text { Volum bak ekualisasi }\left(\mathrm{m}^{3}\right) \\
\mathrm{HRT} & =\text { Hydraulic Retention Time }(\mathrm{jam}) \\
\mathrm{Q} & =\text { Debit air limbah }
\end{aligned}
$$

Dimensi unit constructed wetland dipengaruhi oleh faktor utama yaitu seberapa besar efisiensi pengolahan yang diingingan. Efisiensi dipengaruhi oleh faktor utama yaitu waktu tinggal hidraulik (HRT) seberapa lama air limbah berada pada unit constructed wetland. Permodelan perhitungan waktu detensi di reaktor constructed wetland dengan pendekatan removal BOD/COD [10] , persamaan rumus sebagai berikut :

1) Efisiensi BOD

$$
\mathrm{R}_{\mathrm{BOD}}=\frac{C_{\text {in }}-C_{\text {out }}}{C_{\text {in }}}
$$

Dimana: $\mathrm{R}_{\mathrm{BOD}}=$ Efisiensi pengolahan $\mathrm{BOD}$

$$
\mathrm{C}_{\mathrm{In}}=\text { Konsentrasi influent }(\mathrm{mg} / \mathrm{L})
$$$$
\mathrm{C}_{\text {out }}=\text { Konsentrasi effluent }(\mathrm{mg} / \mathrm{L})
$$

2) Waktu detensi pengolahan BOD

$$
\left(\mathrm{BOD}_{5}\right)_{\mathrm{t}}=\left(\mathrm{BOD}_{5}\right)_{0} \cdot \mathrm{e}^{-0.697 \mathrm{t}}
$$

Dimana: $(\mathrm{BOD})_{\mathrm{t}} \quad=$ Konsentrasi BOD akhir $(\mathrm{mg} / \mathrm{l})$

$(\mathrm{BOD})_{0}=$ Konsentrasi BOD awal $(\mathrm{mg} / \mathrm{l})$

td = waktu tinggal (hari)

3) Efisiensi pengolahan COD

$$
\mathrm{R}_{\mathrm{COD}}=\frac{C_{\text {in }}-C_{\text {out }}}{C_{\text {in }}}
$$

Dimana: $\mathrm{R}_{\mathrm{COD}}=$ Efisiensi pengolahan COD

$$
\begin{aligned}
& \mathrm{C}_{\mathrm{In}}=\text { Konsentrasi influent }(\mathrm{mg} / \mathrm{L}) \\
& \mathrm{C}_{\text {out }}=\text { Konsentrasi effluent }(\mathrm{mg} / \mathrm{L})
\end{aligned}
$$

4) Waktu detensi pengolahan COD

(5)

$$
\mathrm{COD}_{\mathrm{t}}=\mathrm{COD}_{0} \cdot \mathrm{e}^{-0.6401 \mathrm{t}}
$$

$$
\text { Dimana: } \begin{aligned}
(\mathrm{COD})_{\mathrm{t}} & =\text { Konsentrasi COD akhir }(\mathrm{mg} / \mathrm{l}) \\
(\mathrm{COD})_{0} & =\text { Konsentrasi COD awal }(\mathrm{mg} / \mathrm{l}) \\
\mathrm{td} & =\text { waktu tinggal (hari) }
\end{aligned}
$$

\section{Perhitungan Water Balance}

Pada unit Subsurface Consructed Wetland di pengaruhi proses evapotranspirasi dan presipitasi. Proses evapotranspirasi (ET) mengakibatkan berkurangnya kuantitas air, hal ini dikarenakan tanaman memerlukan air dalam jumlah tertentu untuk reaksi photosyntesis. Sedangkan proses presipitasi $(\mathrm{P})$ merupakan bertambahnya kuantitas air akibat pengaruh dari curah hujan. Besarnya nilai air limbah yang keluar di hitung berdasarkan rumus keseimbangan air [7], dapat dilihat pada gambar 2.

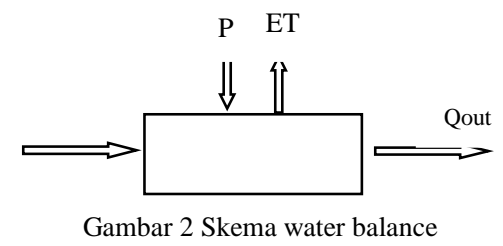

$$
\mathrm{Q}_{\mathrm{o}}=\mathrm{Qi}+(\mathrm{P}-\mathrm{ET}) / \mathrm{A}
$$

Dimana ;

$\mathrm{Q}_{\text {o }}=$ Output air limbah $\left(\mathrm{m}^{3} /\right.$ hari $)$

Qi = Input air limbah $\left(\mathrm{m}^{3} /\right.$ hari $)$

$\mathrm{P}=$ Nilai presipitasi $(\mathrm{mm} / \mathrm{hari})$

ET $=$ Nilai Evapotranspitasi $(\mathrm{mm} /$ hari $)$

$\mathrm{A}=$ Luas Area $\left(\mathrm{m}^{2}\right)$

\section{D.Perhitungan Kehilangan Tekan}

- Perhitungan headloss karena dihitung menggunakan rumus modifikasi Hazzen-William, dengan perhitungan sebagai berikut: 


$$
\mathrm{hf}=\left[\frac{Q}{0,00155 \cdot C \cdot D^{2,63}}\right]^{1,85} L
$$

Dimana: $\mathrm{hf}=$ headloss $(\mathrm{m})$

$$
\begin{aligned}
& \mathrm{Q}=\operatorname{debit}(\mathrm{m} 3 / \mathrm{s}) \\
& \mathrm{C}=\text { koefisien kekasaran } \\
& \mathrm{L}=\text { panjang pipa }(\mathrm{m})
\end{aligned}
$$

- Headloss pada aksesoris dihitung menggunakan rumus Hazzen-William, dengan perhitungan sebagai berikut:

$$
\mathrm{hf}=k\left[\frac{k v^{2}}{2 g}\right]
$$

Dimana:

$\mathrm{Hf}=$ headloss $(\mathrm{m})$

$\mathrm{K}=$ jumlah aksesoris

$\mathrm{v}=$ kecepatan di dalam aksesoris $(\mathrm{m} / \mathrm{s})$

$\mathrm{g}=$ percepatan gravitasi $\left(9,81 \mathrm{~m} / \mathrm{s}^{2}\right)$

- Headloss pada media SSFCW dihitung dengan rumus Darcy sebagai berikut (IOWA, 2007):

$\mathrm{hf}=\frac{Q \cdot A s}{K \cdot h \cdot W^{2}}$

\section{Dimana:}

$\mathrm{hf}=$ headloss $(\mathrm{m})$

$\mathrm{Q}=\operatorname{debit}\left(\mathrm{m}^{3} / \mathrm{s}\right)$

As $=$ Permukaan constructed wetland $\left(\mathrm{m}^{2}\right)$

$\mathrm{K}=$ konduktifitas hidraulik $(\mathrm{m} / \mathrm{d})$

$\mathrm{W}=$ lebar constructed wetland $(\mathrm{m})$

$\mathrm{h}=$ kedalaman muka air $(\mathrm{m})$

- Perhitungan headloss karena kecepatan aliran di unit pengolahan dapat ditentukan berdasarkan persamaan Darcy-Weisbach sebagai berikut:

$$
\mathrm{hf}=f\left[\frac{l v^{2}}{D .2 g}\right]
$$

$$
\begin{aligned}
\text { Dimana }: \text { hf }=\text { Kehilangan tekanan }(\mathrm{m}) \\
\mathrm{f}=\text { koefisien } \\
\mathrm{f}=1.5\left(0.01989+\left(\frac{0.0005078}{4 R}\right)\right. \\
\mathrm{L}=\text { panjang pipa }(\mathrm{m}) \\
\mathrm{V}=\text { kecepatan aliran }(\mathrm{m} / \mathrm{v}) \\
\mathrm{D}=\text { Diameter pipa }(\mathrm{m})
\end{aligned}
$$

\section{HASIL DAN PEMBAHASAN}

\section{A. Kualitas Air Limbah}

Kualitas air limbah grey water di Rusunawa Grudo Surabaya diambil dari pipa effluen limbah dari rumah susun pada tanggal 10 maret, 17 maret dan 24 maret 2016 dan masing-masing diambil pada pukul 06.30 wib - 08.00 wib. Teknik sampling yang dilakukan yaitu dengan metode grab sampling dan pengumpulan sampel secara 'composite' yang merupakan campuran dari beberapa sampel. Pengujian sampel dilakukan di laboratorium Teknik Lingkungan. Berdasarkan hasil sampling digunakan data untuk perencanaan pada tabel 1 sebagai berikut:
Tabel 1. Karakteristik air limbah

\begin{tabular}{ccrrrrc}
\hline Parameter & Satuan & \multicolumn{3}{c}{ Nilai (Influen) } & $\begin{array}{c}\text { Rata- } \\
\text { rata }\end{array}$ & $\begin{array}{c}\text { Baku } \\
\text { Mutu }\end{array}$ \\
\hline BOD & $\mathrm{mg} / \mathrm{L}$ & 139.51 & 213.52 & 193.04 & 182.02 & 30 \\
COD & $\mathrm{mg} / \mathrm{L}$ & 288.32 & 373.14 & 327.96 & 329.81 & 50 \\
TSS & $\mathrm{mg} / \mathrm{L}$ & 80.00 & 120.00 & 110.00 & 103.33 & 50 \\
PH & - & 8.53 & 8.35 & 8.21 & 8.36 & $6-9$ \\
\hline
\end{tabular}

Sumber: Hasil analisa

Data perbandingan karakteristik limbah grey water dapat ditampilkan dalam grafik pada gambar 3 .

Gambar 3. Karakteristik limbah grey water

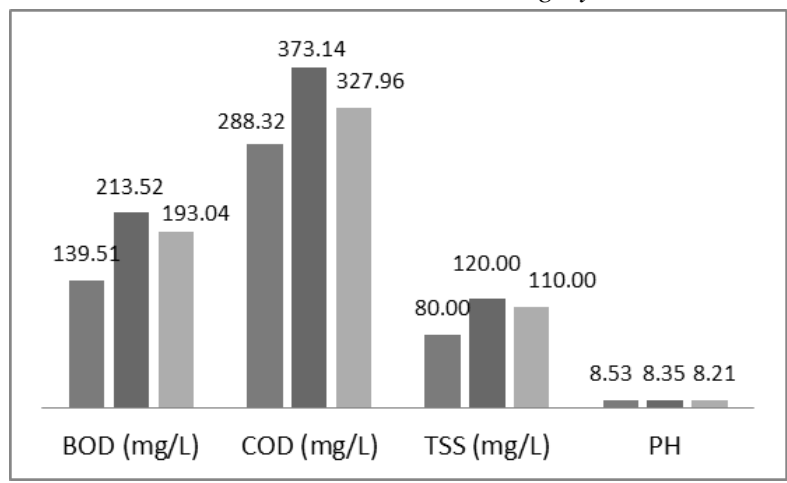

Berdasarkan hasil analisa diatas, data yang digunakan untuk perencanaan sebagai berikut:

$\mathrm{TSS}=103.33 \mathrm{mg} / \mathrm{L}$

$\mathrm{COD}=329.81 \mathrm{mg} / \mathrm{L}$

$\mathrm{BOD}=182.02 \mathrm{mg} / \mathrm{L}$

\section{B. Kuantitas Air Limbah}

Kuantitas air limbah domestik didasarkan dari penggunaan air bersih warga rusunawa. Pemakaian air PDAM diketahui dari analisa meteran induk PDAM rusunawa selama 24 jam. Hasil dari pengumpulan data kuantitas air bersih didapatkan pemakaian air PDAM sebesar $56 \mathrm{~m}^{3} /$ hari. Berikut fluktuasi pemakaian air air di rusunawa Grudo Surabaya pada gambar 4.

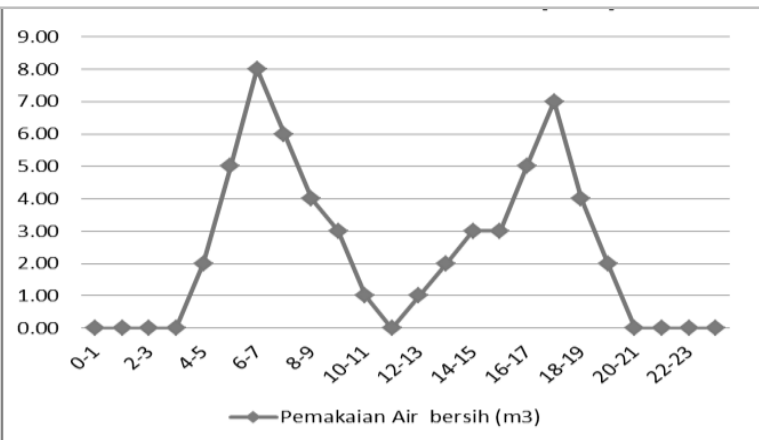

Gambar 4. Fluktuasi pemakaian air bersih

Pada perencanaan ini diterapkan $80 \%$ merupakan angka persentase untuk menentukan air limbah dari proses harian penggunaan air bersih warga rusunawa. Hal ini disesuaikan dengan literatur bahwa debit air limbah dapat perkirakan mencapai $80 \%$ kebutuhan air bersih pada perumahan [12]. Sehingga diketahui debit air limbah harian sebesar 44.8 $\mathrm{m}^{3} /$ hari. Untuk limbah grey water diperkirakan 50-80\% dari total air limbah perumahan [6]. Oleh karena itu dalam perencanaan ini diterapkan $75 \%$ limbah grey water dari total 
air limbah domestik. Di peroleh total debit air limbah grey water rusunawa Grudo sebagai berikut:

$$
\begin{aligned}
\text { Q grey water } & =\mathrm{Q} \text { limbah total } \mathrm{x} 75 \% \\
& =44.8 \mathrm{~m}^{3} / \text { hari } \mathrm{x} 75 \% \\
& =33.6 \mathrm{~m}^{3} / \text { hari }
\end{aligned}
$$

\section{Kesetimbangan}

Penentuan kesetimbangan massa diperlukan untuk menentukan arah massa yang terbebaskan akibat proses pengolahan air limbah grey water dalam IPAL Subsurface Flow Constructed Wetland. Adanya kesetimbangan massa juga berfungsi untuk menentukan sistem operasi dan pemeliharaan intalasi pengolahan. Massa balance IPAL Subsurface Flow Constructed Wetland pada gambar 5.

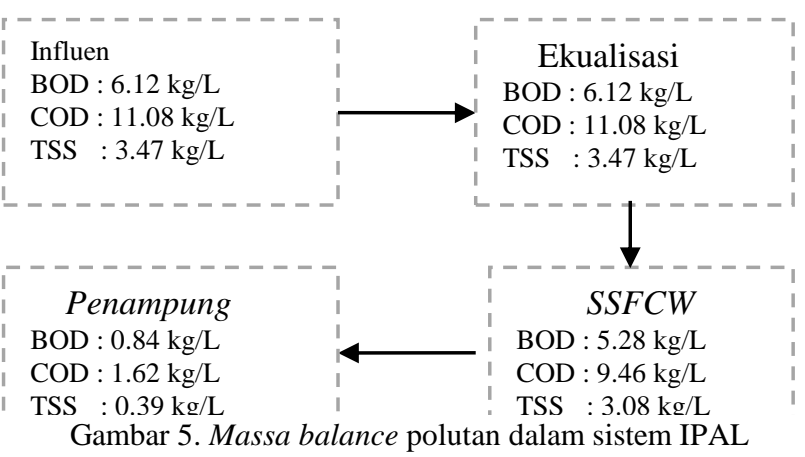

Sesuai dengan diagram alir diatas dijelaskan bahwa penyisihan removal polutan terjadi hanya pada sistem Constructed wetland dengan efisiensi removal sebesar BOD $86 \%$, COD $85 \%$ dan TSS $88 \%$. Konsentrasi efluen yang dihasilkan sebesar BOD $25 \mathrm{mg} / \mathrm{L}$, COD $48 \mathrm{mg} / \mathrm{L}$ dan TSS $17 \mathrm{mg} / \mathrm{L}$.

Sedangkan kesetimbangan massa air akibat pengaruh presipitasi dan evapotranspirasi dihitung dengan rumus pada persamaan, ditampilkan pada gambar 6 .

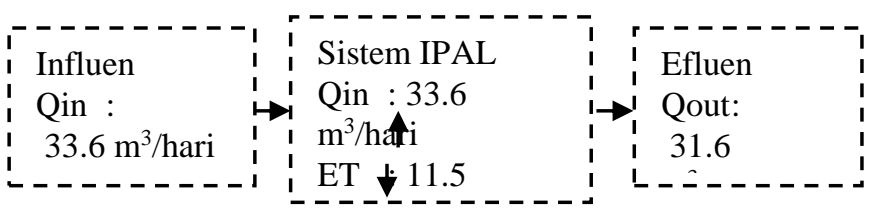

Gambar 6. Kesetimbangan massa air

Berdasarkan diagram alir water balance diatas dijelaskan bahwa nilai Evapotranspirasi didapatkan dari hasil penelitian dengan Cyperus alternifolius disesuaikan dengan temperatur kota Surabaya sekitar $32^{\circ} \mathrm{C}$ [5]. Temperatur tersebut, disesuaikan dengan grafik nilai evapotranspirasi berdasarkan penelitian sebesar $24 \mathrm{~mm} /$ hari [13]. Sedangkan nilai Presipitasi merupakan hasil perhitungan dari data curah hujan Kota Surabaya sebesar $20 \mathrm{~mm} /$ hari. Perhitungan tersebut sebagai berikut:

Evapotranspirasi $\left(\mathrm{ET}_{\mathrm{CYP}}\right)=\frac{24 \mathrm{~mm}}{\text { hari }} \times \frac{1 \mathrm{~m}}{1000 \mathrm{~mm}} \times 480 \mathrm{~m}^{2}$

$=11.52 \mathrm{~m}^{3} /$ hari

Presipitasi (P)

$=\frac{20 \mathrm{~mm}}{\text { hari }} \times \frac{1 \mathrm{~m}}{1000 \mathrm{~mm}} \times 480$

$\mathrm{m}^{2}$

$$
=9.6 \mathrm{~m}^{3} / \text { hari }
$$

\section{D.Perencanaan Unit-unit Pengolah Air Limbah}

Perencanaan IPAL terdiri atas bak ekualisasi, bangunan Subsurface Flow Constructed Wetland, bak penampung akhir, dan sistem perpipaan.

1) Perencanaan Bak Ekualisasi

Bak ekualisasi difungsikan sebagai bak penampung awal untuk menjaga kuantitas debit air limbah yang masuk. Debit atau aliran dan konsentrasi limbah yang fluktuatif akan disamakan debit dan konsentrasinya dalam bak ekualisasi, sehingga memberikan kondisi optimum pada pengolahan selanjutnya. Unit ini direncanakan berbentuk persegi panjang dan pengaliran dari bak ekualisasi ke unit berikutnya (SSFCW) dengan pemompaan agar beban air limbah merata. Perhitungan bak ekualisasi diperoleh dari volume kumulatif dari selisih titik kritis. Nilai untuk titik kritis maksimum adalah 5.8 dan titik kritis minimum adalah -5.8. Berikut grafik bak ekualisasi pada gambar 7 .

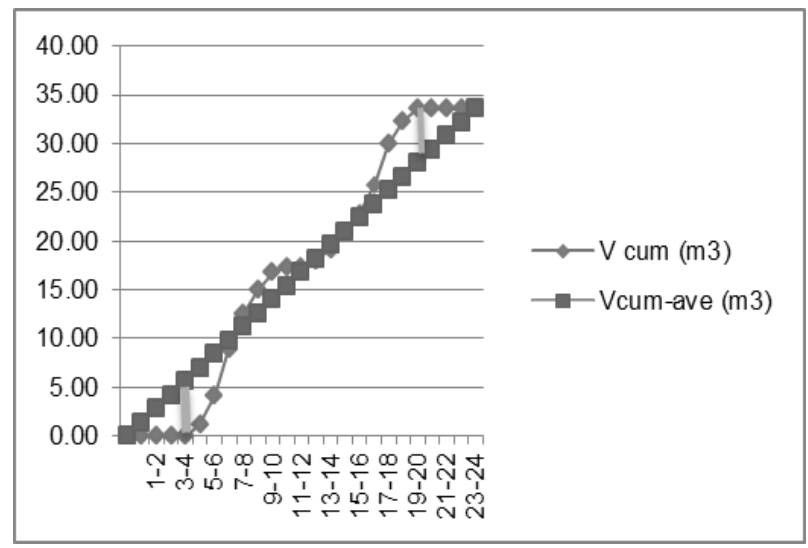

Gambar 7. Volume Kumulatif bak ekualisasi

a) Dimensi Kolam Ekualisasi :

$\begin{array}{ll}\text { - } \text { Volume efektif } & =11.6 \mathrm{~m}^{3} \\ \text { - H rencana } & =2 \mathrm{~m} \\ \text { - } \text { Luas } & =5.8 \mathrm{~m}^{2} \\ \text { - Freboard } & =0,3 \mathrm{~m} \\ \text { - Panjang efektif } & =3.5 \mathrm{~m} \\ \text { - Lebar efektif } & =2 \mathrm{~m}\end{array}$

b) Spesifikasi pompa:
- Merek
: UNILIFT CC5
- Tipe
: M - 1
- Daya
: $0.214 \mathrm{kWt}$
- Debit (flow)
$: 2.178 \mathrm{~m}^{3 / \mathrm{h}}$
- Total Head
: $2.84 \mathrm{~m}$ (5 m max)

Desain unit kolam Ekualisasi dapat dilihat pada gambar 8 dan gambar 9 sebagai berikut.

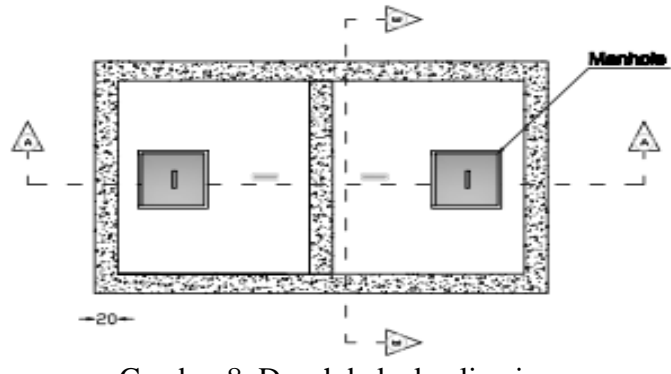

Gambar 8. Denah bak ekualisasi 


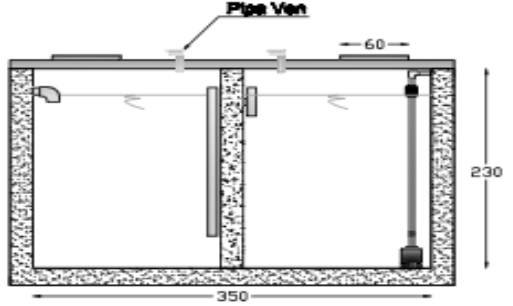

Gambar 9. Potongan bak ekualisasi

2) Perencanaan Unit Subsurface Flow Constructed Wetland Unit Subsurface Flow Constructed Wetland (SSFCW) direncanakan berbentuk persegi panjang dan terbagi atas beberapa kompartmen. Pembagian kompartmen bertujuan untuk meratakan persebaran air dan memudahkan dalam perawatan unit SSFCW. Waktu detensi (HRT) di unit SSFCW selama 3 hari. Tanaman yang digunakan pada unit adalah Cyperus alternifolius dengan kerapatan penanaman dalam $1 \mathrm{~m}^{2}$ terdapat 1 rumpun ( 10-20 stems). Media yang digunakan pada unit ini terdiri dari Medium sand yang digunakan sebagai media melekatnya akar yang tercelup air limbah dan media gravel sebagai penyangga dibagian inlet dan outlet.

Berdasarkan perhitungan teoritis diperoleh spesifikasi unit SSFCW sebagai berikut:
a) $\mathrm{P}$ bangunan efektif
: $48 \mathrm{~m}$
b) L bangunan efektif
$: 10 \mathrm{~m}$
c) Kedalaman air
$: 1 \mathrm{~m}$
d) Freeboard
e) Volume media
$: 0,5 \mathrm{~m}$
f) Area surface
$: 240 \mathrm{~m}^{3}$
$: 480 \mathrm{~m}^{2}$

g) HLR (hidrolic loading rate) : $0.07 \mathrm{~m}^{3} / \mathrm{m}^{2}$. hari

h) BOD loading rate $\quad: 12.75 \mathrm{~g} / \mathrm{m}^{2}$. hari

Desain unit SSFCW dapat dilihat pada gambar 10 dan gambar 11 sebagai berikut.

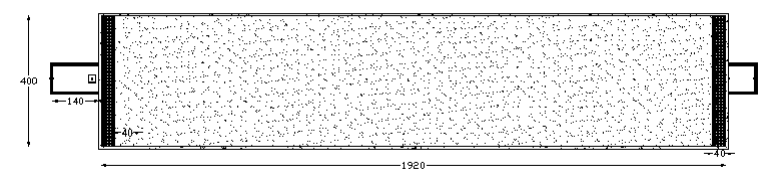

Gambar 10. Denah SSFCW

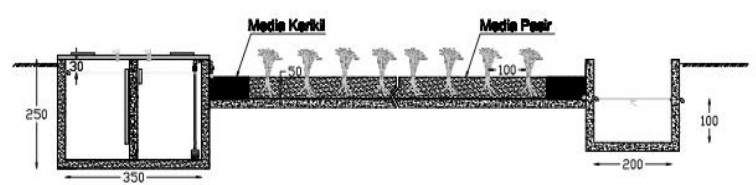

Gambar 11. Potongan SSFCW

3) Perencanaan Unit Kolam Penampung

Unit bak penampung digunakan untuk menampung air olahan dari SSFCW sebelum dibuang ke badan air. Kola mini mempermudah proses operasi dan pemeliharaan khususnya pada proses pengambilan sampel efluen air limbah untuk diuji kensentrasinya disesuaikan dengan baku mutu yang ada.. Maka, diperoleh dimensi kolam penampung sebagai berikut:
a) Volume efektif : :4.2 m3
b) Luas Efektif $\quad: 4.2 \mathrm{~m} 2$
c) Kedalaman air $: 1 \mathrm{~m}$
d) Panjang unit $\quad: 2 \mathrm{~m}$
e) Lebar unit $\quad: 2 \mathrm{~m}$
f)Freeboard $: 0,5 \mathrm{~m}$
g) Tebal dinding : $0.2 \mathrm{~m}$

Desain unit SSFCW dapat dilihat pada gambar 12, dan gambar 13 sebagai berikut.

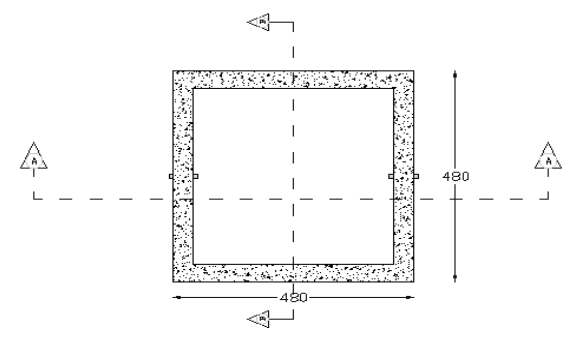

Gambar 12. Denah Kolam Penampung

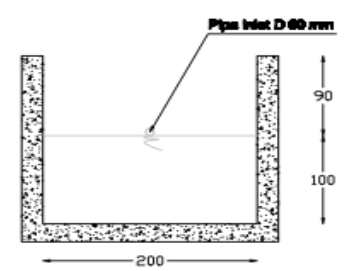

Gambar 13. Potongan Kolam Penampung

\section{E. Perencanaan Sistem Pengaliran dan Profil Hidrolis}

Sistem pengaliran antar unit menggunakan sistem saluran terututup berupa pipa. Penentuan dimensi pipa ditentukan berdasarkan nilai headloss serendah mungkin namun dengan diameter pipa yang tidak terlalu besar, supaya tidak diperlukan nilai slope yang tinggi pada pipa dan mendapatkan pipa dengan harga seefisien mungkin. Perhitungan headloss meliputi perhitungan headloss mayor dan minor pada sistem IPAL. Adapun perhitungan seluruh headloss dalam sistem IPAL ditampilkan dalam Tabel 2.

Tabel 2.

Perhitungan headloss pada sistem IPAL

\begin{tabular}{clc}
\hline No & \multicolumn{1}{c}{ Unit } & Hf \\
\hline $\mathbf{1}$ & Kolam Ekualisasi & $0,0482 \mathrm{~m}$ \\
$\mathbf{2}$ & SSFCW & $0,0687 \mathrm{~m}$ \\
$\mathbf{3}$ & Kolam Penampung & $0,0307 \mathrm{~m}$ \\
\hline
\end{tabular}

Sumber: Hasil perhitungan

\section{F. Operasional dan Maintenance Teknis IPAL}

Pengoperasian dan maintanance IPAL dapat dilakukan dengan beberapa perlakukan yang mendukung sistem IPAL tetap berjalan yaitu:

a) Bak Ekualisasi :

1)Limbah dikumpulkan di kolam ekualisasi.

2) Bak dengan pompa Submersible utama dan cadangan.

3)Pompa dijalankan secara bergantian selama 24 jam

4) Dilakukan pengecekan dan pembersihan pada propeller

5) Arus listrik dalam kondisi mati atau terputus saat dilakukan pembersihan

6) Bak ekualisasi sebaiknya dikuras minimal 2 bulan sekali

b) IPAL Constrcuted wetland

1) Vegetasi yang memiliki nilai estetika

2) Pemanenan tanaman Cyperus selama 7 bulan sekali

3) Pemanenan akan dilakukan dengan pembagian area

4) Pengendapan pada media, akan dilakukan penggantian media yang baru

5) Air olahan dapat dimanfaatkan dan memenuhi baku mutu

c) Kolam Penampung

1) Pengecekan luaran efluen air limbah 
2) Pengecekan kualitas air limbah setiap 1 bulan sekali

3) Sebaiknya dilakukan pengurasan kolam penampung 6 bulan sekali

\section{G.Rencana anggaran biaya (RAB)}

Rencana Anggaran Biaya digunakan untuk menentukan jumlah investasi yang diperlukan untuk pembangunan IPAL. RAB dihitung berdasarkan volume pekerjaan dan Harga Satuan Pokok Kegiatan (HSPK) Kota Surabaya tahun 2015 dikalikan volume pekerjaan. Hasil perhitungan RAB ditampilkan dalam Tabel 3.

\section{KESIMPULAN}

Kesimpulan dari desain IPAL di Rusunawa Grudo sebagai berikut:

a) IPAL Constructed wetland mampu mengolah limbah domestik grey water dengan nilai konsentrasi BOD sebesar $25 \mathrm{mg} / \mathrm{l}$, COD sebesar $48.35 \mathrm{mg} / \mathrm{L}$ dan TSS $11.72 \mathrm{mg} / \mathrm{L}$. Didapatkan desain unit ekualisasi memiliki luas bangunan sebesar $5.8 \mathrm{~m} 2$, unit IPAL Constructed wetland luasnya $480 \mathrm{~m}^{2}$, dan kolam penampung memiliki luas bangunan sebesar $4.2 \mathrm{~m}^{2}$.

b) Terdapat Pedoman Operasional dan Maintenance IPAL Constructed Wetland

c) Angggaran biaya yang dibutuhkan untuk mewujudkan unit IPAL sebesar Rp. 412.059.22

\section{UCAPAN TERIMA KASIH}

Penulis mengucapkan terima kasih kepada dosen

\begin{tabular}{|c|c|c|c|}
\hline No & Uraian Pekerjaan & \multicolumn{2}{|c|}{ Harga Pekerjaan } \\
\hline 1 & $\begin{array}{l}\text { Pembersihan lapangan dan } \\
\text { Pearalatan Tanaman }\end{array}$ & $\mathrm{Rp}$ & $79,679,352$ \\
\hline 2 & Pekerjaan Penggalian Tanah & $\mathrm{Rp}$ & $49,391,719$ \\
\hline 3 & $\begin{array}{l}\text { Pekerjaan Pengurugan pasir } \\
\text { dengan pemadatan }\end{array}$ & $\mathrm{Rp}$ & $9,951,900$ \\
\hline 4 & Pekerjaaan beton K-225 & $\mathrm{Rp}$ & $152,053,309$ \\
\hline 5 & $\begin{array}{l}\text { Pekerjaan Pembesian dengan } \\
\text { besi beton (Polos / Ulir) }\end{array}$ & $\mathrm{Rp}$ & $1,887,785$ \\
\hline 6 & Pekerjaan bekisting dinding & $\mathrm{Rp}$ & $49,323,548$ \\
\hline 7 & Pekerjaan bekisting lantai & $\mathrm{Rp}$ & $37,107,248$ \\
\hline 8 & $\begin{array}{l}\text { Pekerjaan Pondasi Beton } \\
\text { Bertulang (150 kg besi }+ \\
\text { bekisting) }\end{array}$ & $\mathrm{Rp}$ & $1,084,562$ \\
\hline 9 & $\begin{array}{l}\text { Pekerjaan pengurugan tanah } \\
\text { kembali }\end{array}$ & $\mathrm{Rp}$ & 621,165 \\
\hline 10 & $\begin{array}{l}\text { Pekerjaan pengurugan pasir, } \\
\text { kerikil, dan tanaman pada } \\
\text { SSFCW }\end{array}$ & $\mathrm{Rp}$ & $21,857,975$ \\
\hline \multirow[t]{2}{*}{11} & Pompa, Pipa, Aksesoris & $\mathrm{Rp}$ & $9,100,460$ \\
\hline & Total Biaya & $\mathrm{Rp}$ & 412.059 .22 \\
\hline
\end{tabular}

pembimbing dan dosen penguji Tugas Akhir atas saran dan masukan terhadap penulisan jurnal serta kepada Kementrian Ristek Dikti atas beasiswa Bidik Misi angkatan 2012 yang telah mensupport penulis selama masa perkuliahan.

\section{DAFTAR PUSTAKA}

[1] BLH. 2010. Kualitas Air Surabaya Mengalami Penurunan. http://ih.surabaya.go.id./web.blh/? $c=$ main $\& m=$ detail. $\&$ id $=35$, diakses tanggal rabu 30 Desember 2015 pukul 18.40 wib

[2] BLH. 2013. Buku Data Laporan Status Lingkungan Hidup Daerah (SLDH) Kota Surabaya tahun 2013.

http://lh.surabaya.go.id/weblh/?c=main $\& m=$ slhd 2013 , diakses tanggal rabu 30 Desember 2015 pukul 19.40 wib

[3] Crites, R. And Tchobanoglous, G. 1998, Small and Decentralized Wastewater Management Systems: Wetlands and Aquatic Treatment Systems, Mc Graw- Hill, Singapore.

[4] Hesket and Bartholomew, 2001. Constructed wetland, http: // www. Epa. Gov/-owow/wetland/pdf/-overview.pdf.

[5] http://www.accuweather.com/id/id/surabaya/203449/currentweather 203449

[6] Laurence K, Lau. 2009. Guidelines for the Reuse of Gray Water. Departemen of Health Wastewater Branch. State Of Hawai

[7] Leto, C et al.2013. Effects of plant species in a horizontal subsurface flow constructed wetland-phytoremediation of treated urban wastewater with Cyperus alternifolius and Typa Latifolia L.in the West of Sicily (Italy). Departement of Agricultural and Forest Sciences, Universita degli studi di polermo, Viale delle Scienze 13.90128 palermo,Italy

[8] Li,F, Wichman, K. Otterpohl, R. 2009. Review of the Tecnology Approach for Grey Water Treatment and Reuse. Science of the Total Environment. Vol. 407.pp: 3439-2449

[9] Peraturan perundang-undangan Nomor 32 tahun 2009 tentang Perlindungan dan Pengelolaan Lingkungan, setiap kegiatan usaha wajib mengolah limbah dan menjaga ekosistem lingkungan.

[10] Supradata. 2005. Pengolahan Limbah Domestik Menggunakan Tanaman Hias Cyperus alternifolus Dalam sistem Lahan Basah Buatan Aliran Bawah Permukaan. Tesis Magister Ilmu Lingkungan. Semarang: Universitas Diponegoro

[11] Tangahu, B.V dan Warmadewanthi, I.D.A.A.,2001. Pengelolaan Limbah Rumah Tangga Dengan Memanfaatkan Tanaman Cattail (Typha Angustifolia) dalam Sistem Constructed Wetland.Purifikasi. Vol.2, No.3 ITS Surabaya

[12] Tchobanoglous.2003. Wastewater Engineering Treatment and Reuse $4^{\text {th }}$ Edition. New York : Mc. Graw Hill

[13] Tuttolomondo et al, 2014. Effect of plant species on water balance in a pilot-scale horizontal subsurface flow constructed wetland planted with Arundo donax $L$ and Cyperus alternifolius $L$. Two year tests in a Mediterranean environment in the West of Sicily (Italy) Deaprtement of Agricultural and Forest Sciences, Universita degli studi di polermo, Viale delle Scienze 13.90128 palermo,Italy

[14] Wibisono Gunawan, Suswati.2013. "Pengolahan Limbah Domestik Dengan Teknologi Taman Tanaman Air (Constructed Wetlands)”. Indonesian Green Technology Journal.Vol. 2 